\title{
principios de la termofísica del horno vertical de cemento
}

\section{grundlagen der wärmephysik des zementschachtofens}

\author{
H. EIGEN
}

( Zement-Kalk-GIps», 13, nuim, 10, octubre 1960, pag. 458.)

Se desarrollan y explican con ejemplos las ecuaciones sobre el consumo calorífico del homo vertical.

El consumo calorífico por kilo de clínker depende de tres factores:

1. Del intervalo de temperatura $\Delta t$ entre el gas y el material en el límite entre el sistema térmico principal y el sistema secundario.

2. Del factor del Co durante la combustión del cok.

3. De la suma del calor de reacción del sistema térmico principal con el calor del clínker y con las pérdidas de calor por las paredes del sistema término principal.

Aun con un factor de CO elevado, puede reducirse el consumo calorffico por debajo de $800 \mathrm{kcal}$ por kilo de clínker, si el intervalo de temperatura entre el gas y el material se conserva bajo en el límite del sistema. El intervalo de temperatura $\Delta t$ afecta notablemente el consumo calorífico (puede reducirse por medidas apropiadas).

Si se reúnen todas las condiciones favorables, incluso con un contenido de agua de granulación del $11,7 \%$, se puede rebajar el consumo calorífico por debajo de $700 \mathrm{kcal} / \mathrm{kg}$ de clínker.

En la práctica ya se han conseguido $697 \mathrm{kcal} / \mathrm{kg}$ de clínker, a pesar de tener un factor de CO elevado. 